\title{
The Revitalisation of a Craft Economy: The Case of Scottish Knitting
}

\author{
JADE HALBERT \\ University of Huddersfield, UK
}

\section{Keywords:}

Scotland

Knitting

Creative economies

Entrepreneurship

Craft

Internet communities

Aesthetic heritage

Authenticity

\begin{abstract}
In the 1980s, Vivienne Weir knitted for money at home, her skills - little remuneratedrealising in luxurious yarns the fashionable imaginings of a local designer. In 2018 Kate Davies knits at home, her skills the foundation of a successful eponymous knitwear design, yarn production, and publishing business. What separates these women is more than time - in contemporary Scotland, knitting is a valid and valued entrepreneurial pursuit, and so-called home knitters form part of a vast network of crafters whose turn from home craft to design-focused entrepreneurship represents a significant contribution to the £1billion per annum that the fashion and textile industries generate for Scotland.
\end{abstract}

Through analysis of the business activities of both women, collected through personal testimony interviews, this article examines the revitalisation of knitting in Scotland as a viable and lucrative entrepreneurial activity. It compares and contrasts the historical case study of Vivienne who was not afforded the opportunity to realise her potential and make a business from her skills, with the contemporary story of Kate who has translated her skills in hand-knitting and passion for design into a profitable enterprise.

It argues that the revitalisation of the craft economy of knitting in Scotland has been galvanized by the rise of a new generation of knitters determined to rewrite the Scottish aesthetic lexicon in knitwear design, a new appreciation for the heritage and tradition of skilled knitting, and a new-found understanding of the economic, social, and cultural value of knit craft. In an age of increasing automation in fashion and textiles, and 
concerns around the social and environmental impacts of mass-manufacturing, this article demonstrates the importance of a dynamic craft economy in knitting to the Scottish fashion and textile industries.

The article, and the research undertaken, focusses on the particularities of Scottish hand-knitting through the two case studies and the specific context of Scottish developmental initiatives. However, it has also intended to indicate the resonances of this specific research to other instances of the burgeoning of 'traditional' craft practices and products (often undertaken by women) as marketable within a global environment. Such marketability involves complex interactions between notions of the 'traditional', of cultural identity or affiliation and how these might be displayed or affirmed in clothing (by designers/producers and consumers). The notion of 'authenticity' and how this interacts with ideas of innovation and the fashionable are also explored, along with the importance of the Internet and social media to the success, or otherwise, of such entrepreneurial endeavours.

\section{Introduction}

While much valuable research has been undertaken and disseminated recently around the significance of hand-knitting as cultural practice and economic activity in Scotland, both historically and in the contemporary period (Mann 2017, Abrams, Moskowitz, and Chapman, 2016, Butler 2015, Chapman 2015, Abrams 2010), the revitalisation of home-knitting as a catalyst for entrepreneurial activity in modern Scotland has so-far been overlooked. This is not surprising, especially given that it is a relatively recent phenomenon galvanized by the rise of the Internet and the subsequent emergence of a global network of passionate knitters. In 2018, knitting as a creative, design-focused activity is no longer stifled by corporate dictate; instead, the most exciting and innovative designs for knitwear are found through online engagement with the international knitting community. Creative home-knitters and aspiring knitwear designers can share their work through forums such as Ravelry, on social 
media, or on personal websites and blogs, but more than this, they can actually develop lucrative businesses through the same channels.

A vibrant cohort of independent knitwear designers focusing on a distinctly Scottish aesthetic has emerged in recent years, combining an appreciation for craft and the cultural heritage of Scottish knitting with an understanding of fashionability and design integrity. Through the profitable endeavours of such designers (including Kate Davies, Hilary Grant, Di Gilpin, Jade Starmore and many others), and their adroitness in harnessing the power of digital entrepreneurship, knitting has once again come to the fore as a vital component of the creative economy of the country and an important contributor to the more than $£ 1$ billion per annum that fashion and textiles generate for the national coffers (Scottish Enterprise 2017).

This article presents and analyses two divergent histories of would-be knitwear design entrepreneurs based in Scotland - one from the 1980s, and one from the present decade - and

uses their experiences as a lens through which to gain an understanding of how home-knitting as a catalyst to individual economic prosperity in Scotland has been understood and applied since 1980. It offers a new perspective on Scottish knitting as a design industry that is nourished by the Internet and the powerful visual and cultural heritage of the country, while proposing recommendations as to the lessons the international knitting industry can learn from this Scottish example.

\section{Two Stories: The Business of Scottish Knitting}

At the final event in the University of Glasgow-led 'Knitting in the Round: Hand-Knitted Textiles and the Economies of Craft in Scotland' network, Professor Lynn Abrams warmly acknowledged the ways in which scholarly understanding of the culture and practice of Scottish knitting had been enriched through collaboration with knitters and entrepreneurs in the industry: "We recognise that really exciting things happen in research when researchers speak to those who actually practise the skill. The really exciting stuff happens, and the new 
insights occur, when you engage with people who really understand what they're doing” (Abrams 2016). This article heeds that acknowledgment, and places 'those who really understand what they're doing' at the centre of its analysis.

The first-hand personal testimony accounts of two women who have engaged in creative design-led entrepreneurship in Scottish knitting have informed and directed this research. Their testimonies are presented here in a condensed form, and are intended as a contextual grounding and starting point from which to examine the revitalisation in the culture and business of Scottish knitting in recent years, especially as it intersects with entrepreneurial viability and prosperity.

\section{Knitter, Outworker, Trier: Vivienne Weir, 1980-1984}

Vivienne Weir grew up in the 1960s on a peripheral housing estate on the outskirts of Glasgow. With little provision for the outdoor leisure requirements of children, indoor pursuits were important and prime among these was knitting, which she was taught by her mother. She knitted clothes for her dolls, and as she grew older designed and knitted clothes for herself. Having harboured an ambition to be a fashion designer since childhood, her creative expression in this regard found an outlet in hand-knitting at home, experimenting by adapting and refashioning the patterns produced by corporate yarn companies, such as Jaeger and Sirdar.

By the early 1980s, having been made redundant from her factory job, she turned to her hand-knitting skills as a potential source of income. Her first opportunity was found in response to an advertisement in the Glasgow newspaper, the Evening Times, which invited experienced hand-knitters to attend an address in the well-to-do West End of the city. She

did, and came away with yarn, a pattern for a jumper, and instructions to return the completed garment in a week. She spent around three hours a night knitting, and duly returned the 
finished garment to the designer the following week. For this she was paid $£ 15$ - similar jumpers already for sale in the shop, she noted with interest, were selling for $£ 150$.

Vivienne quickly became frustrated knitting someone else's designs for little money. She had glimpsed an exciting and clearly lucrative world of knitwear design, and realised there might be opportunity there to run her own business; after all, she had been designing her own knitwear for some years, and had the knowledge and understanding of how to both devise fashionable designs and knit them. Her plan was to emulate the designer for whom she had worked and concentrate on designing and knitting full-time; in this way, she reasoned, she could fulfil her domestic, economic, and creative needs in one hopeful entrepreneurial endeavour.

Unfortunately, her nascent business did not prosper. She sold a few items through her social and family networks, but, as she stressed in interview, since these were largely lowincome and aesthetically-conservative she was forced to adjust her flamboyant designs, produce garments she did not find inspiring, and sell them at affordable prices - certainly not the $£ 150$ per item she had imagined would be possible. With only a rudimentary understanding of markets, finance, and other fundamental entrepreneurial levers, Vivienne's attempt at turning her home-knitting expertise into a viable design business faltered within months, and did not even make enough profit to repay the capital outlay she had invested in yarn and other essential materials.

Despite her talent as a knitter, her appreciation for design, and her eager enthusiasm, her naivety in business meant she was defeated on all sides. The market for design-led, handknitted products certainly existed; writing in The Guardian, the fashion journalist Brenda Polan commented on the superiority of the new fashionable hand-knits available for sale in London's exclusive independent boutiques: “There are lots of mass-produced [knitted jumpers] in the shops but the most imaginative are the handknits. This is a rapidly growing 
and very successful section of the British fashion industry" (Polan 1980). Despite the attention of the fashion press, however, the market for hand-knits was niche and not easilyaccessible. As an unknown designer, it would have been difficult for Vivienne to penetrate that market in any meaningful way, at least without the benefit of an associated retail business like those exclusive boutiques described by Brenda Polan. There was also the problem of production; while she was interested in design, and saw herself as a budding knitwear designer, what she produced was knitwear - her understanding of 'design' was completely integrated with the material product. This meant that production was slow and dependent on her own efficiency - she had neither the capital nor the knowledge to build her own network of outworkers. By 1984 and the birth of her first child, she had resigned herself to knitting once again in a purely domestic capacity, rather than in the interests of entrepreneurship.

Vivienne's story demonstrates that in the 1980s, while there may have been routes into profitable entrepreneurship in knitwear design from a starting position as a skilled and enthusiastic home knitter and designer, these were often unclear, especially to those with no established brand name, formal training, or understanding of the business world. The highend knitwear design sector was controlled by those with the capital means and commercial nous to start their own businesses selling original designs manufactured by hand-knitting outworkers and sold at exclusive boutiques, or - as was more common - was controlled by the international yarn corporations. The means to harness the cultural and economic power of knitwear design and put it in the hands of knitters themselves was some years off.

\section{Knitter, Designer, Award-Winning Entrepreneur: Kate Davies, 2010-Now}

Kate Davies grew up in a Lancashire mill town where knitting permeated home life. As an academic historian and lecturer in eighteenth-century literature at the University of Edinburgh, for Kate knitting was a hobby that "passed the time on very long commutes and 
during very long departmental meetings" (Kate Davies 2018). Like Vivienne, for Kate her interest in knitting was underpinned by an interest in fashion and clothing. Her skills as a home knitter enabled her to design and make garments for herself that were distinctive, far removed from the humdrum offerings of the corporate knitting-pattern publishers. She developed her own designs to share with the knitting circle she was part of in Edinburgh, and even sold some of these to her online friends as pdf downloads. After a serious stroke forced her to leave her job as an academic, it was to knitting that she turned initially as a therapeutic activity, and which she soon recognised could potentially support her economically.

Within a few short years, Kate built up a small but profitable business as a knitwear designer. The main driver of this business was pdf pattern downloads sold through a free Big Cartel e-commerce account, supported by a strong online presence which she had steadily developed through blogging and social media. It was, therefore, a business that required little capital outlay but did demand an advanced understanding of the digital world and a significant investment of creative labour including designing innovative and attractive patterns, undertaking historical research, writing regularly-updated and engaging editorial content, and fashioning a distinctive creative identity and narrative that would form the foundation of what was to become the Kate Davies Design brand.

Making use of her academic skills, Kate turned her attention to publishing and spent time in Shetland researching the cultural heritage of knitting on the islands, those working to preserve its unique knitting traditions, and the industries that make up this distinctive and vibrant knitting culture. This led to the self-publication of her first book on the subject, Colours of Shetland (2012), which cemented her status as an emergent force in a new generation of passionate and creative knitwear designers based in Scotland. Further books followed, including: Yokes (2014), Buachaille: At Home in the Highlands (2015), The Book of Haps (2016), and Inspired by Islay (2017). Kate's academic background meant she was 
able to use developed skills in research and written communication to harness the internet and to promote her own work and Scottish hand-knitting both online and through book publication. Vivienne Weir, in the 1980s, did not have access to the Internet and social media in order to promote her work; nor did she have an academic background and the skillset and opportunities this afforded to Kate Davies.

Scottish identity has been crucial to the brand's success; combined with her own concern for sustainability and her desire to create a wholly-Scottish company. She invested the profits of her publishing endeavours in the launch of a yarn line, Buachaille, a fine 2-ply worsted yarn made entirely from Scottish wool. This profitable diversification was wellreceived, both in the UK and internationally, and drove the company forward quickly. In 2016 Kate Davies Designs beat intense competition to win the competitive British Micro Business of the Year award. In the same year profits were such that Kate's husband was able to join the company full-time, and she was also able to employ someone else to relieve her of most of the business chores. This allowed her to concentrate on the real strength of the business - original and innovative knitwear design, and the publication of these designs online and in books intended to inspire the global network of knitters who remain entranced by Kate Davies Designs’ particular interpretation of authentic Scottish knitwear.

In 2018, Kate Davies Designs is regarded as a prominent example of the successful revitalisation of Scottish knitting as a design industry. The publishing arm of the business is about to launch its ninth book with more planned for 2019 and beyond, and Buachaille has been joined in the yarn department by Millarochy Tweed, a mohair and wool yarn developed in Donegal but inspired by the colours of the Scottish Highlands. Knitters around the world can order Kate Davies Designs books, patterns, yarns, or full-garment kits, and for the first time the company is targeting non-knitters who want to buy into the Kate Davies aesthetic, 
selling readymade knitwear developed in collaboration with and manufactured by the historic Scottish knitwear company, William Lockie.

From knitting at home, Kate Davies has parlayed skills and passion for knitting into a successful design business that draws on the culture of Scotland and its history as a nation of skilled knitters. While it is clear that she has benefitted from the technological advances of the Internet as a primary route to market, not so clear are the other factors that have galvanised her success in the twenty-first century, and which caused Vivienne to flounder in the 1980s. I will argue that the rise of the Internet alone cannot explain the differences in experience of aspiring knitting entrepreneurs in the intervening years. This article now turns to examine the ways in which knitting has been represented and consumed in the UK and Scotland. It will analyse the efforts to regenerate the domestic Scottish knitting industry following the advent of off-shore production and mass-manufacturing, present the opportunities for entrepreneurship in the industry now, and speculate about the influence of politics, economics, and notions of 'traditional' Scottish culture in the very clear revitalisation of Scottish knitting as a viable, valid, and valuable economic activity.

\section{Adjusting Tension: Representations of Knitting and Knitters}

Despite the recent and very welcome disruption of the stereotypes around knitting (Newington 2014), there has long been tension around the popular cultural representations of knitters and knitting - and indeed, women who work at the needle in any form (Parker 2010) - in the United Kingdom. On one hand it has been disdained in the popular imagination as either a craft rooted in poverty and the necessary clothing requirements of plebeian populations - see for example, Dickens' depiction of the loathsome Madame Defarge and her grim sorority of tricoteuses in A Tale of Two Cities - or as a home-craft, the province of solitary elderly women who knit to pass the time - Agatha Christie's Miss Marple character is a prominent example of this type (Faiers 2014). On the other hand, knitting has also been 
associated with innovation and creativity in fashion design - Elsa Schiaparelli's trompe l'oeil sweaters of the 1930s, Kaffe Fassett's exuberant designs of the 1970s, or Rei Kawakubo's challenging knitted garments of the 1980s, for example.

For a short period there was almost a reconciliation of these seemingly opposing factions: skilled home-knitters on one side, and imaginative young fashion designers on the other. This near-reconciliation found its zenith in the early 1980s when expensive handknitted garments became fashionable, possibly as a reaction against the volume of massproduced cheap imported clothing that was penetrating the British market in this period (Phizacklea 1990). While the imaginative young designer may have had a vision of a spectacular knitted garment, because of the prevailing reputation of knitting as the province of the Miss Marple type, he or (more usually) she was reluctant to learn the craft, and so was often required to call on the expertise of experienced home knitters to actually realise the complex designs - there were precious few who could combine a talent for design with the required knitting skills, at least not with the capacity to meet the demand required for profitable manufacture. ${ }^{1}$ Using largely anonymous outworkers (and publicising the fact) became a short-lived but significant trend in British fashion; in 1980 alone, the fashion pages of The Guardian featured no fewer than eight such companies and journalists delighted to describe the networks of women cheerily knitting 'woollies' at home (Stares, 1980). ${ }^{2}$ Of course, as already indicated, this was also Vivienne Weir's first experience of knitting for money in Glasgow.

While an army of outworking home knitters laboured over innovative designs in luxurious yarns, this did not seem to lead to any significant interest in design on the part of those knitters, or the development of a consumer-led transformation in the fashionability of the knitting patterns available for sale. For the majority, outworking was a chance to make money while doing something they would have done anyway as a hobby; they did not turn 
their skill to design. ${ }^{3}$ As such, despite the clear popularity of knitted garments in the fashion world, and the potential market for fashion-forward knitting patterns to capture the attention of a new generation of knitters who would be interested in self-fashioning through knitting, the stereotypical Miss Marple knitter remained dominant in the market, and therefore the majority of commercially-produced knitting patterns were designed to satisfy that type of knitter. Any would-be-knitter with an interest in fashion would find little in the way of truly fashionable knitting patterns available, either in magazines dedicated to the subject, or in the hundreds of knitting pattern books published every year. ${ }^{4}$ Instead, knitting patterns were (in the main) devised by corporate yarn companies as marketing devices to sell yarn, not as stand-alone products intended to promote a fashionable aesthetic in knitwear. Fashionforward knitwear, therefore, remained the preserve of those who could afford to buy the designer version and with few exceptions, those knitting at home had to make do with the largely dowdy offerings of the commercial yarn companies.

\section{Representations of Scottish Knitting: Harnessing Heritage and Inverting Tradition}

Unlike other types of dress and textiles associated with notions of a romantic Scottish past most obviously the kilt and its associated tartan which have an insidious history (Trevor Roper 1983; Faiers 2008) - Scottish knitting owes its development to a more international practise of craft which defines itself in alignment with the craft customs of its northern European neighbours. The aesthetic characteristics of Scottish knitting share many common elements and motifs with wider Scandinavian and Celtic (Irish, Cornish, Faeroe Isles, etc.) knitting design, and all owe their knitting heritage in some ways to what Hobsbawm calls ‘invented tradition' (1983). But as Tseëlon (2015: 127) argues, “even when collective markers of identity are recent constructions or fabrications, they can still signify people's genuine sense of shared meaningful collectivity", and this can certainly be applied to the 
resurgence of Scottish knitting as a design sector in recent years. But (perhaps uniquely among its neighbours), Scotland has a long-standing reputation for a wide variety of highquality and distinctive knitted goods. Among these, as Bennett notes, are "kilt hose and stockings, Sanquhar gloves, Fair Isle jumpers [and] Shetland lace shawls" (1981: 3).

After devolution in 1997, the Scottish Government had more control over the ways in which traditional crafts - including knitting - should be supported. In common with the rest of the United Kingdom, the country's fashion and textile industries had suffered the effects of the global financial crisis in the early 1990s and the move to overseas production which had started in earnest in the 1970s and increased rapidly, with Scottish manufacturing in fashion and textiles almost obliterated by the end of the twentieth century. One contemporary report joint-commissioned by the Scottish Executive, the Enterprise and Lifelong Learning Department, and the Scottish Textiles Network, however, showed that the knitting industry (while suffering a loss in volume terms) had actually retained a consistent presence over the decade since 1987, accounting for a steady $23 \%$ share of total industry employment (Pieda Consulting 2000). This consistency could be attributed to the historic legacy of Scottish investment in business and enterprise knowledge among craft producers in the preceding decades (Moar and Fraser 1982), or to the fact that the bulk of the Scottish knitting industry over this period had remained devoted to high-quality niche production of cashmere and other luxury products, which had stayed relatively stable as the fortunes of those invested in “lower value fibres" faltered and eventually failed (Pieda Consulting 2000: 9).

Despite its voracious take-over of almost all fashion production, low-cost massmanufacturing has never been successful at replicating the essence of Scottish knitting 'authenticity' is its cornerstone, both in design and in fibre. ${ }^{5}$ Pringle of Scotland is a case in point here; at one time among the grandest of Scottish knitwear design and manufacturing businesses, after it was purchased by a Hong Kong-based conglomerate in 2000 and the bulk 
of its production moved out of Scotland to reduce costs in 008, its appeal within the market was reduced. Recent industry reports confirm that the company has now traded at a loss for eleven consecutive years (McCulloch 2017). The Scottish connection, in terms of location and yarn integrity, therefore, is a valuable asset and has largely protected the domestic knitting industry from the threat of low-cost production. The strong association with quality and luxury has also gone some way to safeguarding the integrity of the industry and allowed entrepreneurs to take advantage of "niche and premium markets where the Scottish product is considered to offer higher levels of both quality and authenticity" (Scottish Enterprise 2017). Many Scottish knitwear design entrepreneurs have succeeded in harnessing this reputation to differentiate their products from others in the market; as Abrams has stressed, "In a world in which distinction matters [...] authenticity perhaps lends an item superior advantage" (Abrams, 2016). This 'authentic' distinction has been expressed aesthetically by contemporary knitwear entrepreneurs through dedication to Scottish yarns and the inversion of traditional Scottish visual tropes. Galashiels-based Eribé Knitwear, for example, produce collections that pivot around the notions of quality and authenticity central to Scottish knitwear by using native yarns and marketing that waxes lyrical about manufacturing according to "knowledge handed down from one generation to the next" (Eribé 2018), thereby invoking the powerful concept of tradition and heritage. The use of colour at Eribé, however, - vibrant, clashing, and unequivocally modern - challenges the muted Scottish palette (which would have traditionally have been muted and derived from natural fleeces and dyes) and has been instrumental in the company's international success. Kate Davies uses traditional Gaelic or Scots words to name her yarns, and writes elegant prose to describe the landscapes and histories that have inspired her designs, but in place of traditional motifs (Fair Isle, or Arran for example), she invokes the shapes and shades of the landscape around her Carbeth studio to consciously invent new traditions; her recent best-selling Carbeth Swan 
Dance sweater pattern being a good example of this. By crafting a narrative that invokes the Scottish landscape and Scottish history to explain the impetus for each garment she designs, Davies has cultivated a loyal market that values this Scottish connection. In areas with a more entrenched knitting culture, for instance the Shetland Isles where knitting has been a key driver of the local economy since the nineteenth century (Chapman 2015), traditions are inverted and invented in more subtle, and arguably more imaginative ways. Ella Gordon, the young Shetland native and rising star of the Scottish knitwear industry takes inspiration from the dramatic socio-economic changes in Shetland in the 1970s after the discovery of North Sea oil, producing collections that draw heavily on a 1970s aesthetic, and embody an idea of "novelty clashed with tradition" (Davies 2016: 81). Of course, there remain those dedicated to preserving the unique culture of Shetland knitting. Among those working to commission (for the royal families of the UK and Norway among others) producing exceptionally fine Shetland lace are Ina Irvine and Emma Isbister, a 97-year-old knitter whose work represents the acme of intricate and complex Shetland lace (Davies 2016).

Collectively, the work that has emerged from Scottish knitwear designers over the last decade exemplifies the exciting shifts in how Scottish knitwear has been viewed and consumed internationally. There is a common visual lexicon - found in colour, yarn, and technique - that inverts tradition and connects each designer's work explicitly to Scotland, but through their efforts that lexicon has been modernized and has evolved in response to market demands. Yes, it retains the valuable characteristics of quality and authenticity through use of native high-quality yarns, but enhances this through a design practice that is outward-facing, modern, and innovative.

\section{Refreshed and Revitalised: Scottish Knitting Then, Scottish Knitting Now}

Since the turn of the present decade there has been concerted effort by the Scottish Government in collaboration with national partners including Creative Scotland, Scottish 
Enterprise, Scottish Development International, Skills Development Scotland, Higher Education, Sector Skills Council, Highlands \& Islands Enterprise, and individual craft entrepreneurs themselves to maintain the economic and cultural momentum currently enjoyed by the Scottish knitting industry. This has been achieved in various ways. As already described, developing a market through explicitly making connections between the sites and stories that inspire and the actual product (and therefore invoking the valuable currency of 'heritage' and 'tradition') has been a key strategy of most successful Scottish knitwear designers in recent years (Weave Consult 2012). This strategy has been a largely successful, and the connection between craft creativity and ideas of national heritage have in recent years been supported by the international success of the television show, Outlander, and the SNP government's dedication to engaging the Scottish diaspora through its themed 'Homecoming' years, the most recent focused on Innovation, Architecture and Design (2016) and History, Heritage and Archaeology (2017). These efforts have led to the emergence of a Scottish identity expressed in crafts, particularly knitting, that retains the visual signature expected by traditionalists, but which is modern and innovative, tuned-in to international market demand.

Governments, however, no matter their intentions, have little power to regenerate creative industries. Revitalisation of creative sectors such as fashion or knitting is almost totally dependent on strong cultural incentives and viable consumer markets. In the case of Scottish knitting these have been nurtured in various ways. Firstly, as already discussed in the case of Kate Davies Designs, the advance of the Internet and its usefulness in the creation and maintenance of global consumer networks cannot be underestimated. While yearning for non-screen-based leisure pursuits has been put forward as a possible reason for the growth in demand for Scottish crafts (BOP Consulting 2012), this denies the clear evidence to support the fact that knitting as a creative craft activity is largely consumed on screen, discussed on screen, and celebrated on screen - the global network of knitters engaging with Scottish 
knitting online have been the driving force in its resurgence. As a consequence, a new and vibrant market of knitters interested in independent creative design has been formed and sustained through participation in knitting blogs, websites, and other online channels and as such the online connection has become a key feature of twenty-first century knitting culture. This goes some way to explaining why more than any other needle craft, knitting has been successful in harnessing screen power and exploiting the advantages of the ever-changing digital world.

Furthermore, while one Highlands and Islands Development Board report of 1974 lamented crafters' inability to transform their unique skills into viable products, and howled with indignation about how those in the craft sectors were not concentrating enough on the object of their work - that is, making objects that sell (Pirnie 1974) - the Internet has facilitated innovation and enterprise by the current cohort of digitally-savvy knitter-designerentrepreneurs. The digital downloadable knitting pattern is the ultimate Scottish product. It is a sustainable, inexpensive, and low-carbon footprint ambassador for the Scottish knitting industry. The majority of Scottish knitting products sold are not, in the main, garments themselves, but patterns for those garments. This shift from knitting product as material object to knitting product as design for a material object has been instrumental in the current prosperity enjoyed by the industry.

Secondly, the Scottish diaspora represents a powerful international market that is keen to engage with Scottish culture, and is deeply invested in notions of Scottish heritage as these intersect with personal identity. While diasporic markets can now easily access and consume Scottish knitwear online, another avenue by which they have been targeted is in so-called 'textile tourism'. Tourists (predominately from the diasporic communities in Canada, America, New Zealand and Australia) come to Scotland to tour the main production centres of Scottish textiles and crafts. Many small producers in areas with a strong textile or knitting 
heritage have benefitted significantly from these markets; the Shetland Islands, for example, has enjoyed a marked increase in textile tourism in recent years (Weave Consult 2012). Kate Davies Designs and other enterprising Scottish design businesses have been able to intervene in this market through a kind of virtual textile tourism; evocatively-written blogs and publications describing landscape, history, and traditions accompanied by high-quality photography has allowed those interested in Scotland and Scottish design (but without the funds to actually visit), to participate in 'textile tourism', at least vicariously.

Thirdly, the influence of knitters themselves. The current cohort of knitwear designers either based in Scotland or claiming allegiance to its aesthetic heritage has been instrumental to the industry's revitalisation. What Kate Davies and others have achieved with their creative knitting products (be those garments, patterns, or yarns), represent exceptionally clever marketing. They have harnessed the globally recognisable, 'authentic' Scottish aesthetic and shaped it into a viable craft commodity that can be disseminated and traded globally at the click of a button. Another noteworthy feature of these businesses is that having developed from interaction with other knitters, they are completely integrated with their market, sharing the same interests and values. The idea of authenticity is the linchpin of this vital integration between the producers and the consumers of Scottish knitwear - in many cases, they are one and the same. Maintaining meaningful interaction with their markets remains fundamental to the future prosperity of this distinctive and creative industry sector; Kate Davies, for example, actively engages via social media with the thousands of people around the world who buy her products. Scottish knitwear has come to embody a type of Scottish culture that can easily be purchased as a digital download and quickly transformed (provided the purchaser has the skills) into an authentic Scottish product that can be worn, declaring affinity to Scotland or claims to Scottish identity and heritage. In 2018, the purchase of a Scottish knitting pattern and the act of using that pattern to knit a garment and 
clothe yourself embodies everything the authors of the Strategy for the Textiles Industry in Scotland report were aiming for in 2010, encompassing 'design innovation and ethical business practices with the desire for luxury and authenticity' (Textiles Scotland: 10).

\section{Conclusion}

Vivienne Weir's attempt to create a business as an independent knitwear designer in the 1980s failed through a combination of factors. Unlike Kate Davies, she did not have easy and immediate access to a global market through the Internet. Nor did she recognise the value of Scottish heritage and tradition expressed in craft as a solid base upon which to build her business; instead she was focused on positioning herself in the fashion industry and building her success on a fleeting trend for hand-knitting. Even if she had attained a moderate level of success in 1980 when hand-knitting as a fashion product reached its apogee, it would have been unlikely to endure beyond a few years. She was also limited by her focus on producing a material product - the idea that she could instead concentrate on pure design and produce knitting patterns rather than knitted garments was an alien concept at that time. Knitting was not then, as it is now, consumer-led; as Kate Davies emphasised in interview, knitters themselves have in recent years influenced the ways in which knitting design is produced and taken control of new ways of thinking in terms of creative preference. Unlike in the 1980 s when international commercial yarn companies controlled the knitting design and pattern industries, now patterns and designs for knitwear have become important "in and of themselves" (Kate Davies, personal correspondence). Moreover, Vivienne entered the business at a time when the penetration of cheap imported mass-produced fashion in the British market meant that most consumers were detached from the manufacturing process and so had stopped recognising the value of the labour involved in creating hand-knitted clothing. As such, they were reluctant to part with their money for those products which were understandably expensive. Furthermore, concerns about the sustainability of mass- 
manufactured cheap clothing had barely formed at that time; now these concerns are dominant in the consumer conscience and the sustainability of the Scottish product (whether pattern or garment) is an attractive quality for many consumers.

Were Vivienne an enthusiastic entrant to the knitting industry now, it is likely her fate would be rather different. The intervening years have witnessed an unprecedented revitalisation in how Scottish knitting is represented, produced, and consumed. The industry today is bolstered by access to global markets via the internet; the Scottish government considers the creative industries - including knitting - a key priority sector, offering investment and support and setting ambitious targets for growth, year-on-year (MacDonald 2012); and while knitting may have suffered the reputational penalty of being seen as a hobby for elderly women in the past, it is now recognised as one of the country's most vital and valuable emerging creative sectors. Some things have remained constant: most obviously the focus on quality and skill and a deep respect for the traditions of knitting, but, as one Shetland-focused report made clear, the cultural and political environment in which the knitting industry operates has changed considerably and for the better in the period under examination here. The focus of the industry has shifted, as this research has shown, from small-scale craft production of material products "towards design and technical innovation, with investment in branding and product differentiation from mass-market goods" (Weave Consult 2012: 8), at the very forefront of entrepreneurial efforts. And while the revitalisation of Scottish knitting as a profitable design sector may have its foundations in what Hobsbawm and others would call the 'invented traditions' of a wider northern European craft heritage, perhaps - given the evidence presented here - there is much to recommend 'invented traditions' in craft and design, and their importance in both cultural and commercial contexts.

\section{Contributor details:}


Dr Jade Halbert is a lecturer in fashion business and cultural studies in the Department of Fashion and Textiles, University of Huddersfield, UK. She is an historian of the British fashion industry with particular research interests in entrepreneurship and family businesses in the industry since c.1800. Awarded her PhD in the Department of History at the University of Glasgow in 2018, she is currently working on a monograph based on her thesis, 'Marion Donaldson and the Business of British Fashion, 1966-1999'.

\section{References}

\section{Primary sources}

Interview with Vivienne Weir, Glasgow, July 2015

Interview with Kate Davies, Carbeth, April 2018

Personal correspondence with Kate Davies, April 2018

\section{Secondary sources}

Abrams, Lynn (2016, March 5), 'Welcome: Knitting in the Round', presented at Authenticity in culturally based knitting, Shetland Museum and Archives, Shetland.

Abrams, Lynn, Moskowitz, Marina, and Chapman, Roslyn (2014-2016), Knitting in the round: hand-knitted textiles and the economies of craft in Scotland, research network funded by the Royal Society of Edinburgh. University of Glasgow, Glasgow.

Abrams, Lynn (2010), Myth and materiality in a woman's world: Shetland, 1800-2000. Manchester: Manchester University Press.

Bennett, H.M. (1981), The origins and development of the Scottish hand-knitting industry (unpublished doctoral thesis). University of Edinburgh <www.era.lib.ed.ac.uk/handle/1842/6842>

BOP Consulting (2012), Craft in an age of change <www.creativescotland.com/_data/assets/pdf_file/0011/21413/Craft-in-an-Age-ofChange-Scotland-Summary.pdf $>$

Butler, R.W. (2015) 'Knitting and more from Fair Isle, Scotland: small-island tradition and micro-entrepreneurship', in G. Baldacchino (ed) Entrepreneurship in small island states and territories, London: Routledge.

Chapman, Roslyn (2015), The history of the fine lace knitting industry in nineteenth and early twentieth century Shetland (unpublished doctoral thesis), University of Glasgow, Glasgow.

Davies, Kate (2016), Shetland oo: wool, textiles, work, Edinburgh: Kate Davies Designs Ltd. Eribé (2018), Our Story, accessed 08 October 2018, <http://www.eribe.com/uk/our-story>.

Faiers, J (2008), Tartan, Oxford: Berg.

Faiers, J (2014), 'Knitting and Catastrophe', Textile, 12: 1, pp.100-109.

Hobsbawm, Eric and Ranger, Terence (1983), The Invention of Tradition, Cambridge:

Cambridge University Press. 
MacDonald, S. (2012), 'Joined up creativity: creative industries and Scotland's urban and rural creative economy', in MacDonald, S. (ed.), Designs on democracy: architecture and design in Scotland post devolution, London: Zero Books.

Mann, J. (2018), 'Knitting the archive: Shetland lace and ecologies of skilled practice', Cultural Geographies, 25: 1, pp. 91-106.

McCulloch, S (2017, November 1), 'Famous Scottish knitwear brand posts £4.9m loss’, Insider.co.uk. <www.insider.co.uk/company-results-forecasts/pringle-scotland-posts49m-loss-11446009>.

Moar, L and Fraser, N (1982), 'Scotland's craft industry: quality not quantity', Quarterly Economic Commentary, 8: 1, pp. 28-37.

Newington, Linda (2014), "In the Loop": Challenging and Disrupting the Stereotypes of Knitting', Textile, 12: 1, pp.8-17.

Parker, Rozika (2010), The Subversive Stitch: Embroidery and the Making of the Feminine, London: I.B. Tauris.

Peach, A (2007), 'Craft, souvenirs and the commodification of national identity in 1970s Scotland', Journal of Design History, 20: 3, pp.243-257.

Pieda Consulting (2000), Briefing paper on the Scottish textile and clothing industry. Edinburgh: Scottish Executive Enterprise and Lifelong Learning Department and Scottish Textiles Network.

Pirnie, D (1974), Designer craftsmen in the Highlands and Islands - proposal for development, Highlands and Islands Development Board.

Phizacklea, A. (1990), Unpacking the fashion industry, London: Routledge.

Polan B, (1980, November 12), 'Knit picking', The Guardian, p. 9

Scottish Enterprise (2017, October). Scottish Economic Facts, <www.scottishenterprise.com/ /media/se_2013/documents/scottish\%20economic\%20facts\%20\%20october\%202017\%20(1).doc?la=en>.

Stares, J (1980, February 8), 'Stitching a way to success in mohair: Judith Stares reports on enterprise in home-knitting' The Guardian, p. 14

Trevor-Roper, Hugh (1983), 'The invention of tradition: The Highland tradition of Scotland', in The Invention of Tradition, E. Hobsbawm and T. Ranger (eds), Cambridge: Cambridge University Press, pp. 15-41.

Tseëlon, Efrat (2015), “'Strikking'/'Knitting History’: Permanent exhibition, Norsk Folkemuseum/folk museum, Oslo, Norway', Critical Studies in Fashion and Beauty, 6: 1, pp. 125-133.

Weave Consult (2012), Shetland textile sector review $<$ www.shetland.gov.uk/economic_development/documents/ShetlandTextileReviewFi nalReport.pdf>.

\footnotetext{
${ }^{1}$ This was not unique to knitwear - British fashion designers, especially fashion graduates of the art schools in the 1980s were often unconcerned with the manufacturing practicalities of their designs and saw the skills needed for realising their often fantastical ideas as far
} 
subordinate to their own artistic design skills. For more on this see Angela McRobbie (1998), British fashion design: Rag trade or image industry? London: Routledge.

${ }^{2}$ Many knitwear companies and designers still use outworkers for hand-knitting, although very few companies actively publicise the fact, and indeed, it has sometimes been treated at many fashion houses as a closely-guarded secret. See for example, S. Williams, (1996) 'That designer jumper you're wearing? Where did it come from?', The Independent, 24 Feb. Recognition of the work of outworkers is increasing now, however. At In The Loop 4: From Craft to Couture, (University of Glasgow, Aug. 2015), the topic of outworkers, their skills, and how they are valued and remunerated provided rich material for debate among delegates. Rosemary Eribé, founder of Eribé Knitwear eloquently defended her use of outworking handknitters and spoke with passion about their contribution to the revitalisation of the Scottish knitwear industry.

${ }^{3}$ There are some exceptions to this. As described in The Independent (1996), many of the outworkers knitting for established design houses actually translated designer sketches into material objects through their superior technical skills, but this has not led to those knitters striking out as designers in their own right; for the most part, they seemed content to remain anonymous knitters working in the interests of design houses.

${ }^{4}$ This is not to suggest that there was no fashion influence on knitting patterns at all - the popular and widely-available Vogue knitting books are testament to this - rather, the point being made here is that since the market was still perceived as conservative, the designs offered in these books represented a diluted version of fashion, not quite the cutting-edge innovation that was seen on the catwalks.

${ }^{5}$ With the exception, of course, of Parisian haute couture and other niche, artisanal and bespoke fashion products. 